\title{
¿Entrainment in a Simulated Supercell Thunderstorm. Part I: The Evolution of Different Entrainment Mechanisms and Their Dilutive Effects
}

\author{
Sonia Lasher-Trapp, ${ }^{a}$ Enoch Jo, ${ }^{a}$ Luke R. Allen, ${ }^{a}$ Bryan N. Engelsen, ${ }^{a}$ And Robert J. Trapp ${ }^{a}$ \\ ${ }^{a}$ Department of Atmospheric Sciences, University of Illinois at Urbana-Champaign, Urbana, Illinois
}

(Manuscript received 28 July 2020, in final form 18 April 2021)

\begin{abstract}
The current study identifies and quantifies various mechanisms of entrainment, and their diluting effects, in the developing and mature stages of a simulated supercell thunderstorm. The two stages, differentiated by the lack or presence of a rotating updraft, are shown to entrain air by different, but related mechanisms that result from the strong vertical wind shear of the environment. The greatest entrainment rates in the developing stage result from the asymmetric overturning of large eddies near cloud top on the downshear side. These rates are greater than those published in the literature for cumuli developing in environments lacking strong shear. Although the entrainment rate increases exponentially in time throughout the developing stage, successive cloud turrets help to replenish some of the lost buoyancy and condensate, allowing the nascent storm to develop further. During the mature stage, the greatest entrainment rates occur via "ribbons" of horizontal vorticity wrapping around the rotating updraft that ascend in time. The smaller width of the ribbons in comparison to the wider storm core limits their dilutive effects. Passive tracers placed in the low-level air ingested by the mature storm indicate that on average $20 \%$ of the core contains some undiluted air from below the storm base, unaffected by any entrainment mechanism.
\end{abstract}

KEYWORDS: Supercells; Entrainment; Convective storms; Cloud resolving models

\section{Introduction}

The American Meteorology Society's (2020) Glossary of Meteorology defines entrainment as "the mixing of environmental air into a preexisting organized air current so that the environmental air becomes part of the current." In an active cumulus cloud, the "preexisting organized air current" is the cloud updraft that originates below its base. Overturning eddies at upper levels at the cloud edges mix in drier "environmental air" that results in evaporation and sublimation of cloud water and ice, respectively, within the cloud and reduces the cloud buoyancy. Such a reduction of condensate and buoyancy is considered here to be dilution, wherein cloudy parcels within the updraft deviate from their adiabatic state. ${ }^{1}$ Entrainment can slow, or even halt, cloud

\footnotetext{
${ }^{1}$ Dilution and entrainment do not necessarily scale equivalently, as entrained air can have properties modified from the environmental air by the presence of the cloud itself (e.g., Dawe and Austin 2011a; Yeo and Romps 2013; Moser and Lasher-Trapp 2017; Hannah 2017).
}

๑ Denotes content that is immediately available upon publication as open access.

Allen's current affiliation: Center for Geospatial Analytics, North Carolina State University, Raleigh, North Carolina.

Engelsen's current affiliation: Environmental Resources Management, Inc., Rolling Meadows, Illinois.

Corresponding author: Sonia Lasher-Trapp, slasher@illinois.edu development to greater depths, as well as precipitation formation. Detrainment, the transfer of cloudy air to the environment, where it evaporates/sublimates and thus humidifies and cools environmental air, is also of importance. This process leads to the initiation of downdrafts at the sides of a small cumulus cloud, produces regions of humid air surrounding clouds, and can in time alter the stability of the local environment.

The atmospheric science community has pursued two general themes when studying cumulus entrainment. The first consists of understanding the mechanisms of entrainment that are important for predicting cloud/storm development and the microphysical processes leading to precipitation. Early studies focused on entrainment and/or dilution due to the dynamics of thermals, plumes, or jets. Reviews of these studies such as those of Turner (1986), Blyth (1993), and the introductory sections of Langhans et al. (2015) and Morrison and Peters (2018), summarize many of the relevant issues. The current study is meant to contribute toward this first theme of understanding how entrainment occurs. The second theme, concerned with parameterizing unresolved atmospheric convection and its effects in largerscale weather and climate models, requires a broader view of entrainment. Details of the mechanisms of entrainment are considered not as important as gauging its overall impact (dilution) upon vertical fluxes of heat, moisture and momentum, cloud depth and opacity, surface precipitation, and the environmental characteristics of an entire column in the atmosphere. Reviews by Arakawa (2004) and de Rooy et al. (2013) discuss the pertinent issues and developments of this theme. Recently, some studies have begun to address the details of entrainment mechanisms to help improve large-scale parameterizations (e.g., Romps and Kuang 2010; Hernandez-Deckers and Sherwood 2016, 2018), 
merging the two historically different themes of entrainment studies.

The focus of this study is upon investigating the mechanisms of entrainment in arguably the most extreme form of cumulus: supercell thunderstorms, produced in environments with strong vertical wind shear that promote rotating storm updrafts. These storms are capable of generating severe weather hazards including hail, heavy rain, and tornadoes over their multihour lifetimes. Because entrainment can deplete the water mass available to produce rain and hail, an enhanced understanding of entrainment in supercell thunderstorms may help improve prediction of their rainfall and hailfall. However, it has been widely held among the scientific community that supercells experience limited entrainment. Within supercell updrafts that typically span depths near $10 \mathrm{~km}$, observational evidence for undiluted cores exists from instrumented balloon ascents (e.g., Bluestein et al. 1988), aircraft penetrations (Musil et al. 1986), and ozone tracer studies (e.g., Boe et al. 1992).

In the only study of direct calculations of entrainment in supercells to date, Peters et al. (2020a, hereafter PNM20) examined idealized, high-resolution numerical simulations of deep convection in environments with various amounts of vertical wind shear. Using the Romps (2010) method for calculating entrainment over 10 -min periods in their simulations, they indeed found smaller fractional entrainment rates (i.e., the ratio of entrained mass flux to updraft mass flux, indicating the extent of the dilution of the updraft) in supercell thunderstorms compared to nonsupercell storms. Earlier studies had shown that the width/area of supercell updrafts increases with increased vertical wind shear (Kirkpatrick et al. 2009; Warren et al. 2017; Trapp et al. 2017; Marion and Trapp 2019; Peters et al. 2019a), and PNM20 argued that the wider updraft cores of supercells limit the "reach" of entrainment into their interior, much like the classical cloud radius dependency of entrainment/dilution (e.g., Simpson et al. 1965) based on laboratory studies of thermals, plumes and jets in environments lacking vertical wind shear.

PNM20 did not explore how [i.e., the mechanism(s) by which] the entrainment occurred in their simulated storms. Information on how supercells entrain, and at what rates (irrespective of their updraft widths), is still lacking. Lilly (1986) proposed that supercell updrafts should resist turbulence breakdown like helical flows, possibly limiting the importance of overturning eddy circulations for entrainment, but PNM20 discounted that hypothesis showing similar calculated spectral profiles of turbulence between their simulated supercell and nonsupercell storms. They thus assumed supercells entrain like continuous, turbulent plumes.

PNM20 could not examine entrainment at the initial stages of their simulated supercell storms. Their use of a "warm bubble" (Klemp and Wilhelmson 1978) in their idealized simulations to initiate the storm, a common practice in supercell studies, artificially and abruptly forces the required vertical acceleration. This practice renders the representativeness of the earliest times of the simulation questionable (and have thus historically been ignored in the analysis; Loftus et al. 2008). However, entrainment by thermals in cumuli growing in highshear environments is of interest, because it may be even more effective than in environments with less or no wind shear. Vertical wind shear imposes an asymmetry in the thermal motions, first noted in observations of shallow trade wind cumuli by Malkus (1949) and later in developing cumuli by Heymsfield et al. (1978), that likely influences entrainment. The "reach" of the overturning thermal circulations, and thus the introduction of environmental air into the cloud core, should necessarily be greater if its circulation is larger on the downshear side. Kitchen and Caughey's (1981) tethered balloon observations of asymmetric toroidal circulations showed eddy overturning was reduced on the upshear side, and enhanced on the downshear side, yielding a circulation that can be envisioned like a capital "P"' (relative to a wind shear vector pointing to the right). Within thermals simulated in a sheared environment by Peters et al. (2019b), the calculated buoyancy was generally less than that in thermals growing in an environment lacking shear, but Peters et al. did not directly evaluate entrainment rates.

If shear-induced asymmetric thermals do enhance cloud dilution, one might question how supercells occurring in such environments can ever develop. Weather forecasters acknowledge anecdotally that the initiation of deep convection is more difficult in higher-wind-shear environments. Peters et al. (2019b) evaluated vertical momentum budgets and found thermals in a sheared environment have slower ascent rates due to an increased downward-directed pressure gradient force, rather than enhanced dilution from entrainment. However, their simulations did indicate enhanced dilution in the higher-shear environment, and if so, this dilution must sometimes be overcome to allow convection to develop further and to produce precipitation in such an environment. The updrafts of supercells are strengthened (and prolonged) by precipitation fallout to the ground that not only decreases hydrometeor loading in the updraft, but also produces the gust front and subsequent enhanced lift of air at its leading edge that helps sustain the updraft (e.g., Klemp 1987). It remains unclear how the potentially enhanced entrainment and dilution in cumuli within a high-shear environment might be overcome to produce the first precipitation needed to strengthen and sustain the updraft. One possibility is that simulated by Kirshbaum (2011) in a lowshear environment, where successive cloud turrets ascended through the saturated wakes of their predecessors, entraining some of their detritus and thus mitigating their dilution and allowing deep convection to develop. Such effects have been studied in smaller cumuli in weakly sheared environments (e.g., Ludlam 1952; Mason and Jonas 1974; Roesner et al. 1990; Blyth and Latham 1993; Ovtchinnikov and Kogan 2000; Moser and Lasher-Trapp 2017).

In summary, a review of the literature suggests that an environment with strong vertical wind shear can potentially have two opposite effects on entrainment and dilution of clouds and storms. On the one hand, it could enhance entrainment and dilution in cumuli potentially developing into supercells, by producing asymmetrical thermal circulations that reach far into their interiors and dilute them effectively, limiting precipitation production that is essential for strengthening the updraft of the nascent supercell. This entrainment and dilution might be overcome by successive cloud turrets. On the other 
hand, strong vertical wind shear could limit entrainment and dilution of mature supercell thunderstorms by virtue of their rotating and/or wider updrafts, favoring precipitation development. The mechanisms by which entrainment acts in both cases, and how their strength and effectiveness in diluting the cloud/storm core compare, is not well established, and may supply general knowledge on entrainment processes in environments lacking wind shear as well. In the current study, the first part of a series, an examination of entrainment and dilution in the developing and mature stages of a single, numerically simulated supercell storm is presented in detail, to begin to address these seemingly contradictory effects of high-shear environments.

\section{Methods}

\section{a. Model description and setup}

The simulation is produced using Cloud Model 1 (CM1) version 19.6, an idealized, nonhydrostatic, three-dimensional cloud-resolving model (Bryan and Fritsch 2002). The model domain is $176 \mathrm{~km}$ in the east-west direction, and $100 \mathrm{~km}$ in the north-south direction, with a constant grid point spacing of $100 \mathrm{~m}$ in horizontal and vertical directions to resolve turbulent eddies of similar sizes in all directions. The subgrid-scale turbulence scheme is that of Deardorff (1980). Liquid and ice microphysics are predicted using the NSSL microphysics parameterization (Mansell et al. 2010; Mansell and Ziegler 2013), a two-moment scheme with six hydrometeor classes: cloud water, cloud ice, rain, snow, graupel, and hail. Other settings of the model are listed in Table 1.

The simulation is initialized with the Weisman and Klemp (1982) thermodynamic sounding (Fig. 1), with a mixed-layer water vapor mixing ratio of $14 \mathrm{~g} \mathrm{~kg}^{-1}$. The vertical wind profile has weaker southerly winds near the surface, veering with height and increasing in speed to westerly near $2.5 \mathrm{~km}$ above the surface (i.e., a quarter-circle hodograph; Weisman and Rotunno 2000). The $0-6-\mathrm{km}$ bulk vertical wind shear is $32 \mathrm{~m} \mathrm{~s}^{-1}$. The environment is initially horizontally homogeneous.

To perturb the hydrostatic base state and initiate convection, a surface-based Gaussian heat flux (e.g., Klaassen and Clark 1985; Carpenter et al. 1998; Moser and Lasher-Trapp 2017) was added to CM1. This heat flux is strongest near the surface and exponentially decreases in magnitude radially and vertically. The horizontal width and height of the Gaussian function are 5000 and $1500 \mathrm{~m}$, respectively. The heat flux linearly increases in time from $0 \mathrm{Wm}^{-2}$ at the start of the simulation to $500 \mathrm{~W} \mathrm{~m}^{-2}$ at $5 \mathrm{~min}$. This amplitude is maintained for $24 \mathrm{~min}$, then linearly decreases to zero over $1 \mathrm{~min}$, for a total of $30 \mathrm{~min}$ of active heating. This heating enables the formation of buoyant thermals which eventually merge and produce the thunderstorm. This more gradual ramp up of forcing, as opposed to the buoyant bubble (Weisman and Klemp 1982) or updraft nudging techniques (Naylor and Gilmore 2012) which typically place the maximum perturbation or forcing near the level of free convection (LFC), allows for a more natural generation of turbulent eddies, and a slower and more realistic transition from buoyant, sheared cloud turrets to a mature supercell. A test simulation where the storm was initiated
TABLE 1. Summary of model parameters used in the simulation.

\begin{tabular}{|c|c|}
\hline $\begin{array}{l}\text { Microphysical } \\
\text { parameterization }\end{array}$ & $\begin{array}{l}\text { NSSL two moment (Mansell et al. } \\
\text { 2010) }\end{array}$ \\
\hline $\begin{array}{l}\text { Horizontal and vertical } \\
\text { advection schemes for vectors }\end{array}$ & Sixth order \\
\hline Scalar advection & Fifth order \\
\hline Artificial diffusion & $\begin{array}{l}\text { Monotonic version applied to } \\
\text { all variables }\end{array}$ \\
\hline $\begin{array}{l}\text { Subgrid-scale turbulence } \\
\text { scheme }\end{array}$ & TKE (Deardorff 1980) \\
\hline Pressure solver & $\begin{array}{l}\text { Klemp and Wilhelmson (1978) } \\
\text { time splitting, fully explicit }\end{array}$ \\
\hline Lateral boundary conditions & Open radiative \\
\hline Maximum forcing in Gaussian & $500 \mathrm{~W} \mathrm{~m}^{-2}$ \\
\hline Domain size & $176 \mathrm{~km} \times 100 \mathrm{~km} \times 20 \mathrm{~km}$ \\
\hline Grid spacing & $100 \mathrm{~m}$ in all directions \\
\hline Time step & $0.5 \mathrm{~s}$ \\
\hline
\end{tabular}

with a 5-km-wide bubble produced a single, broad turret that developed overturning entraining eddies much more slowly, producing an average entrainment rate in the early stages of the simulation approximately one-third that of the case where the Gaussian initiation was used (Engelsen 2018).

Based on the often turbulent nature of entrainment (e.g., Turner 1986), resolving turbulent eddies is necessary to quantify it accurately. Experimentation with larger grid spacings (200 and $500 \mathrm{~m}$ ) showed that only the $100-$ and $200-\mathrm{m}$ grid spacings visually exhibited overturning circulations influencing entrainment that are discussed later in this study (section 5a). Recent studies have suggested that a grid spacing of $250 \mathrm{~m}$ or less is necessary to resolve an inertial subrange in turbulent flows associated with deep convection (Bryan et al. 2003; Petch 2006; Lebo and Morrison 2015). Here, the differences in entrainment calculations among simulations with smaller grid spacings did decrease, but did not yet converge between 100 and $200 \mathrm{~m}$. Smaller grid spacings would have been desirable here especially during the developing stage of the storm, but were impractical for studying the entire, multihour, large-domain simulation.

\section{b. Determination of the different stages for analysis}

The respective time periods of the "developing" and "mature" stages used for the analysis must first be specified. The developing stage begins at the time of the first appearance of the predefined storm core (discussed in section 2c) and ends when a rotating updraft is detected (explained below). At the cessation of the storm-splitting process, when the two counterrotating updrafts separate into two visually detached core surfaces, the mature stage begins. Only the supercell with the cyclonically rotating updraft is analyzed. Later, the cold pool initiates new convective cells that interact strongly with (and thus alter the flow into) the storm. To avoid this complication, the mature stage analysis is ended at this time.

The technique of Naylor et al. (2012) using the modified Pearson correlation (MPC) detects a rotating updraft and objectively determines the end of the "developing stage." The MPC is calculated over $3 \mathrm{~km}$ by $3 \mathrm{~km}$ horizontal subsets of grid points over the entire domain as 


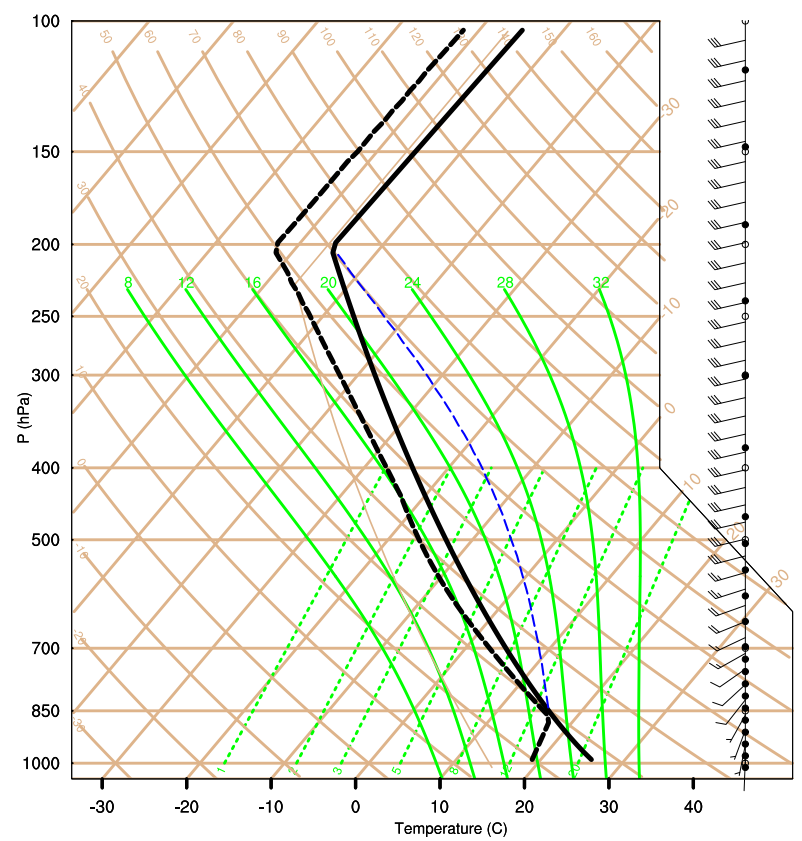

FIG. 1. The environmental sounding used for the simulation. Thermodynamic profile based on Weisman and Klemp (1982); vertical wind profile as shown. The $0-6-\mathrm{km}$ bulk shear is $32 \mathrm{~m} \mathrm{~s}^{-1}$, and the $0-3-\mathrm{km}$ storm-relative helicity is $170 \mathrm{~m}^{2} \mathrm{~s}^{-2}$. Convective available potential energy (CAPE) enclosed by dashed blue line is $2200 \mathrm{~J} \mathrm{~kg}^{-1}$.

$$
\mathrm{MPC}=\frac{w^{\prime} \zeta^{\prime}}{\sigma_{w} \sigma_{\zeta}},
$$

where $w$ is the vertical velocity, $\zeta$ is the vertical component of vorticity, $\sigma$ is the standard deviation of each variable over each horizontal subset, and primed quantities represent deviations from the mean value in each subset. To ensure the MPC is evaluating vorticity within updrafts, $40 \%$ of the grid points in a subset must have a value of $w$ exceeding $7 \mathrm{~m} \mathrm{~s}^{-1}$. The MPC is computed at each level between 2- and 5-km altitudes, and then vertically averaged. When any vertically averaged subset has an MPC value exceeding 0.3 , a rotating updraft is deemed present, ending the developing stage.

\section{c. Entrainment calculations}

The technique for direct calculation of entrainment is that of Dawe and Austin (2011b), also used by Moser and LasherTrapp (2017, 2018). The airmass flux into a cloud core is calculated, where the cloud core is defined as contiguous locations where the vertical velocity and the total hydrometeor mixing ratio (including cloud water, cloud ice, rain, snow, graupel and hail) both exceed a set of predetermined thresholds.

Because the range of updraft speeds and hydrometeor mass contents during the developing and mature stages differ greatly, the core is defined differently at each stage. For the developing stage, the core definition requires vertical velocity exceeding $2 \mathrm{~m} \mathrm{~s}^{-1}$ and total hydrometeor mixing ratio (all liquid and ice combined) exceeding $0.5 \mathrm{~g} \mathrm{~kg}^{-1}$. Numerous tests conducted with different thresholds did not significantly alter the results, but a lower vertical velocity threshold allows an earlier start to the analysis. During the developing stage, entrainment calculations include all cores detected in any of the cloud turrets at that time. In the mature stage, lower thresholds become quite noisy, so the core is defined as a contiguous region having vertical velocity exceeding $20 \mathrm{~m} \mathrm{~s}^{-1}$ and total hydrometeor mixing ratio exceeding $2 \mathrm{~g} \mathrm{~kg}^{-1}$. (The base of the core thus lies above the base of the storm). These values ensured temporal continuity of the supercell core while also capturing the mechanisms of entrainment; higher core thresholds miss some entrainment sources as the core boundaries approach the center of the updraft. Only the single largest core is analyzed during the mature stage; to isolate it within the subset of the domain containing the right-moving supercell, an object identification routine in MATLAB's Image Processing Toolbox ("bwconncomp") is used.

For the prespecified cores at each stage, entrainment $(E)$ and detrainment $(D)$ are calculated as

$$
\begin{aligned}
E-D= & \rho_{(k)} \frac{d V_{(i, j, k)}}{d t}+\rho_{(k)} u_{(i+1, j, k)} W_{x(i+1, j, k)}-\rho_{(k)} u_{(i, j, k)} W_{x(i, j, k)}+\rho_{(k)} v_{(i, j+1, k)} W_{y(i, j+1, k)}-\rho_{(k)} v_{(i, j, k)} W_{y(i, j, k)} \\
& +\frac{1}{2}\left[\rho_{(k)}+\rho_{(k+1)}\right] w_{(i, j, k+1)} W_{z(i, j, k+1)}-\frac{1}{2}\left[\rho_{(k)}+\rho_{(k-1)}\right] w_{(i, j, k-1)} W_{z(i, j, k-1)},
\end{aligned}
$$

where $\rho$ is the moist air density; $V$ is the volume of the grid cell containing the core; $u, v$, and $w$ are the (total, not perturbation) velocity components of the flow; $W$ is the surface area of the core contained in the grid cell; and $i, j$, and $k$ are grid point indices corresponding to the $x, y$, and $z$ directions, respectively. Positive changes in the core volume $(d V / d t)$ can be a source of entrainment, as the core expands and engulfs air. Conversely, negative changes in the core volume are a source of detrainment, as the core shrinks and abandons air originally inside it. All other terms relate to horizontal or vertical mass flux of air into (or outside) the core surface by winds at the core edges. A critical component of this method is that all grid boxes are subdivided into 48 tetrahedrons, to better resolve the core surface on a subgrid scale, reducing some of the limitations of the model grid spacing. A net positive value on the left-hand side of Eq. (2) within a grid box containing the core edge is considered entrainment; a net negative value is detrainment.

The entrainment algorithm is run on the model output so additional tests/refinement can be performed without having to rerun the entire simulation. This requires high temporal resolution in the model output fields (every $6 \mathrm{~s}$ ), due to sometimes rapid changes of the core volume with time. A 1-min-averaged entrainment rate is then calculated using ten 6-s samples. 
The entrainment algorithm cannot distinguish between the vertical mass flux (the updraft) into the base of the core and the mass fluxes (entrainment) into the core sides. Thus, the raw output from the entrainment algorithm is masked in vertical profiles presented later, because these values partly represent air already in the updraft. For the purposes of this study, environmental air that enters the core boundary above the LCL of a surface-based parcel is considered to be entrained, because it has different temperature and moisture properties from the air entering below the LCL. (This distinction is arguably artificial and differs from past studies, ${ }^{2}$ but helps to isolate the contribution by different entrainment mechanisms.) When integrated values of entrainment are presented, the integration begins above a specified altitude ( $2 \mathrm{~km}$ for the developing stage, and $4 \mathrm{~km}$ for the mature stage) to avoid erroneously counting the vertical mass flux of air into the core base that is already within the updraft. As a result, some of the lateral entrainment occurring at the sides of the core over this depth is missed in the integrated values. Passive tracers, discussed in the next section, are used to help diagnose the quantity of air entrained over this depth from above the LCL.

\section{d. Analysis of dilution}

Cloud microphysics studies have historically evaluated the diluting effects of entrainment on nonprecipitating cumulus clouds by comparing measured/simulated liquid water content with the adiabatic value calculated at the same altitude above cloud base (e.g., Warner 1955; Raga et al. 1990; Blyth et al. 2005; Gerber et al. 2008). To place the results found here in context with past studies using this measure of dilution in nonprecipitating clouds, the maximum liquid water content within each turret during the developing stage is compared to the adiabatic value.

Precipitation fallout and the presence of ice precludes using the adiabatic liquid water content to diagnose dilution during the mature stage. Thus, passive tracers were placed into various layers in the simulated storm environment (e.g., Romps 2010; Bryan and Morrison 2012; Peters et al. 2019a) to gauge the dilution of the low-level air ingested during the mature stage of the storm. The tracers are initialized at the model start time with a value of $1.0 \mathrm{~kg} \mathrm{~kg}^{-1}$, are advected by the flow within the domain, and are replenished at the (open) lateral boundaries of the domain. To diagnose the amount of dilution of air ingested from only beneath the storm base (such as from a surface-based adiabatic parcel entering the base), one set of tracers is uniformly distributed from the surface up to the height of the LCL $(1.2 \mathrm{~km}$, based on a surface-based parcel from the environmental sounding), hereafter denoted as "bLCL air." Another set of tracers is distributed into the $1 \mathrm{~km}$ layer directly above the LCL to diagnose the air entrained into the core over that depth, hereafter denoted as "aLCL air."

\footnotetext{
${ }^{2}$ Such distinction differs from some studies that consider air entering the storm from the side, above the LCL, to be considered part of the updraft, for example, within the "effective inflow layer" (Thompson et al. 2007; Peters et al. 2020b).
}
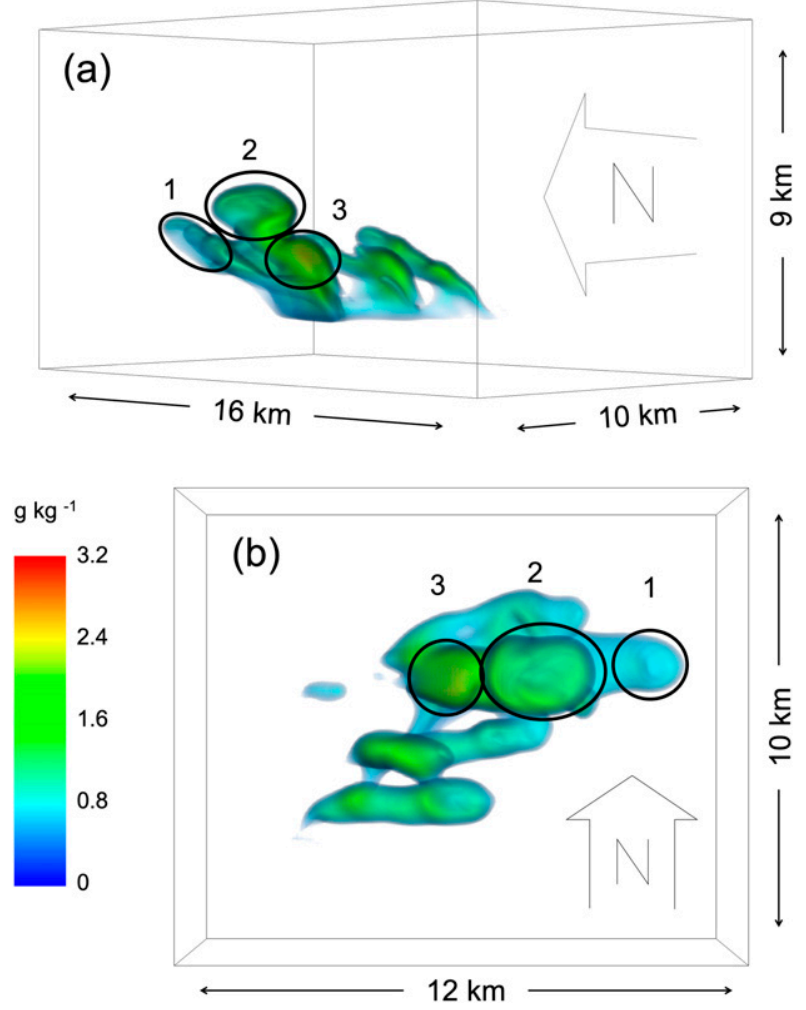

FIG. 2. Three-dimensional renderings of cloud water mixing ratio ( $\mathrm{g} \mathrm{kg}^{-1}$; legend at left) at $67 \mathrm{~min}$ into the simulation as viewed (a) from the side (northwest) and (b) from above. Each black circle contains a region associated with one of the dominant turrets described in the text, numbered in order of first appearance in the simulation. Each rendering only shows a portion of the model domain as labeled.

\section{Overview of the simulation and entrainment rates}

A brief overview of the simulation is now presented to explain its progression through the two stages, and particularly the "developing stage," which has not been examined in the literature with the storm initiation method used here. The developing stage begins at approximately $50 \mathrm{~min}$ into the simulation when multiple cloud turrets exist, having thermal circulations visually identifiable near their tops. The turrets generally translate northeastward, with newer turrets forming to the southwest of preexisting ones, but eventually overtaking and merging with their predecessors. Five distinct cloud turrets are in the domain near the end of the developing stage; three of these (Fig. 2) have the greatest influence on the storm development. The maximum updraft speed over the domain (Fig. 3a) shows the influence of each of the three dominant turrets. The maximum cloud-top height increases steadily throughout the developing stage (Fig. 3b), reaching $6 \mathrm{~km}$ at the end, when one broad updraft and downdraft exists due to the merger of the second and third turrets (Fig. 3d). A rotating updraft is detected at $71 \mathrm{~min}$, ending the developing stage. The "mature stage" (Fig. 4) begins at 96 min into the simulation, when the cores of the anticyclonically rotating 

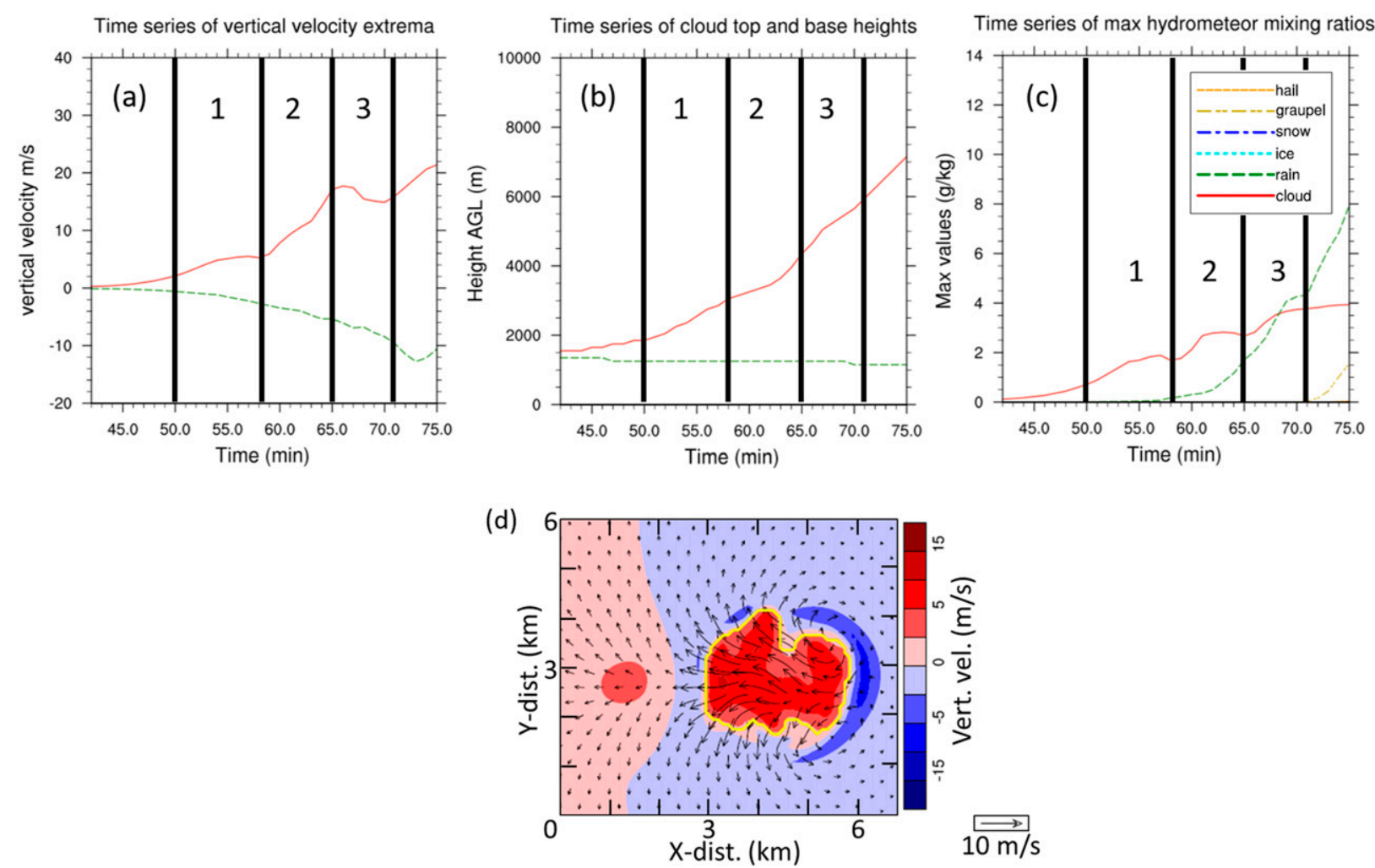

FIG. 3. Time series of (a) vertical velocity minima and maxima, (b) cloud-top and cloud-base heights, and (c) maximum hydrometeor mixing ratios between 42 and $75 \mathrm{~min}$. Vertical lines farthest left and right denote the start and end of the developing stage, with intervals marked by the dominant turret in that period. (d) A horizontal cross section at 5050-m altitude and 70 min (near the end of the developing stage), showing updraft speed (shaded), core detected by the algorithm (yellow contour), and perturbation horizontal wind vectors with scale shown.

and cyclonically rotating storm are visually separate. The cyclonically rotating storm moves on a generally eastward trek across the domain at approximately $15 \mathrm{~m} \mathrm{~s}^{-1}$ during the analysis time. The analysis of the mature stage is terminated at $175 \mathrm{~min}$, before new convection initiates at the leading edge of the cold pool.

The developing and mature stages clearly evolve differently (Fig. 5) and give context to the effectiveness of entrainment during the developing stage versus the mature stage. Updraft speeds remain below $20 \mathrm{~m} \mathrm{~s}^{-1}$ during the developing stage but are consistently near $60 \mathrm{~m} \mathrm{~s}^{-1}$ during the mature stage (Fig. 5a). The core volume is much smaller in the developing stage (Fig. 5b), despite lower thresholds used to define it, whereas the core volume increases dramatically (sevenfold) during the mature stage. The precipitation mass (rain, graupel, and hail) within the core is very small during the developing stage (Fig. $5 \mathrm{c}$ ), but it

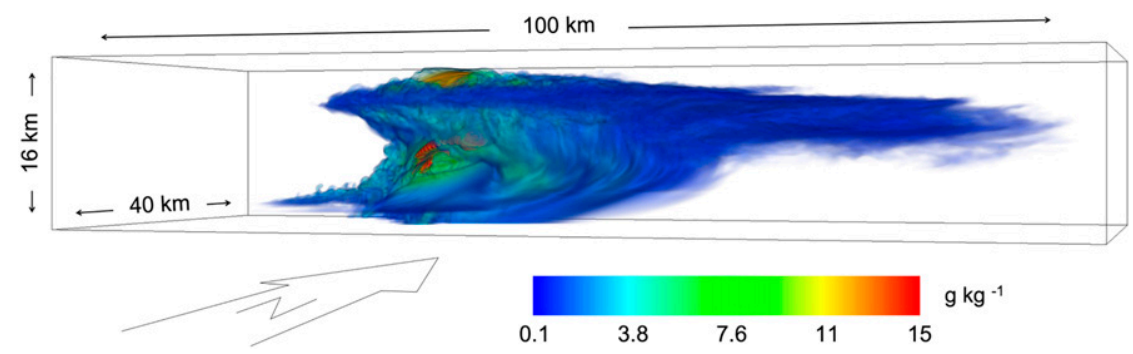

FIG. 4. Three-dimensional rendering of the mature stage of the cyclonically rotating storm, as viewed from the SSE, at $129 \mathrm{~min}$ into the simulation. Values of total hydrometeor mixing ratio are shaded as indicated in legend, with some transparency to visualize farther into the interior of the core. 

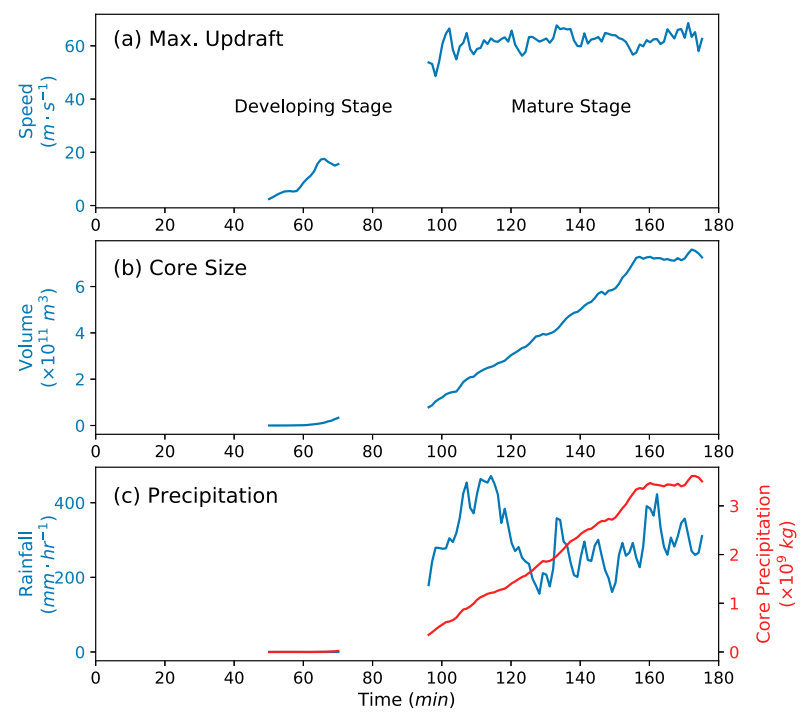

FIG. 5. Time series of 1-min averages of (a) maximum updraft speed, (b) core volume, and (c) rainfall rate at the surface (left side of each panel) and precipitation mass in the core (right side of each panel), for the analyzed portion of the entire simulation. Curves for developing stage and mature stage labeled in (a).

increases nearly an order of magnitude during the mature stage. Precipitation production is insufficient to reach the ground during the developing stage, while rainfall rates during the mature stage range from 200 to nearly $500 \mathrm{~mm} \mathrm{~h}^{-1}$.

The total mass of entrained air (Fig. 6a) increases nearly exponentially during the developing stage, and then continues to increase within the single large core during the mature stage, but more erratically. As turbulence becomes more developed in the simulation and stronger turrets emerge, entrainment rates (Fig. 6b) ${ }^{3}$ greatly increase, even when normalized by the increasing amount of total core surface area. The fractional entrainment rates during the developing stage (Fig. 6c) in this sheared environment surpass similar calculations for a single cumulus congestus developing in environments lacking shear (e.g., Romps 2010; Yeo and Romps 2013; Moser and LasherTrapp 2017) by as much as a factor of 2 .

During the mature stage, the entrainment rate often exceeds that at the end of the developing stage (Fig. 6b), despite the more stringent core definition that would relatively decrease the entrainment rates. The high entrainment rates at the start of the mature stage may yet include artifacts of the storm splitting, as they are never attained again in the analysis period. From the beginning to the end of the mature stage, the

\footnotetext{
${ }^{3}$ Entrainment rates such as these are not often presented in the literature [although rates normalized by core volume rather than surface area can be found, for example, in Yeo and Romps (2013)]. They are useful to evaluate the relative importance of different entrainment mechanisms, as opposed to the more commonly reported fractional entrainment, which can vary due to changes in the updraft mass flux alone without a given change in local entrainment rates.
}
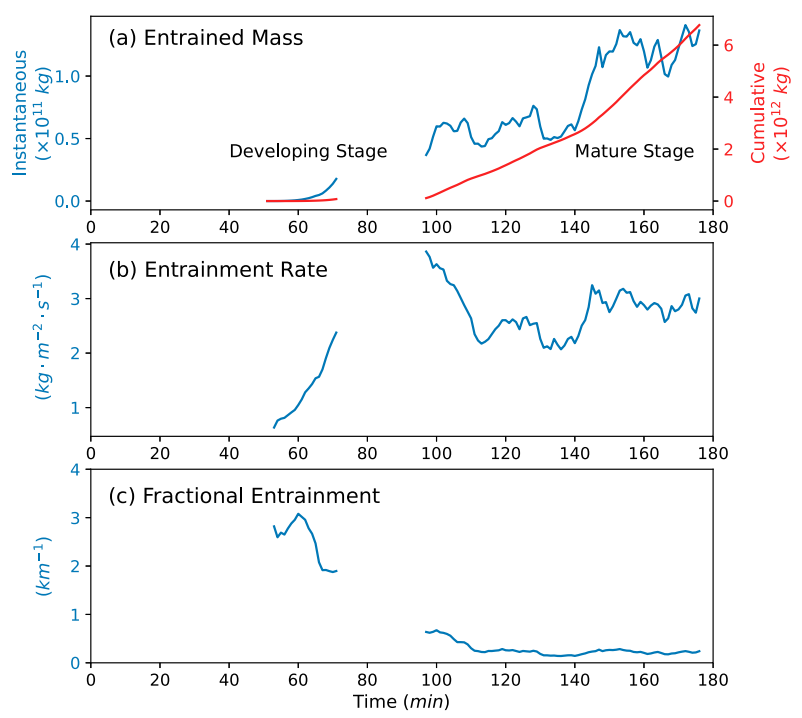

FIG. 6. As in Fig. 5, but for time series of 1-min values of (a) total entrained mass of air (left side of each panel) and cumulative amount (right side of each panel), (b) average entrainment rate normalized by core surface area, and (c) fractional entrainment rate. All entrainment values calculated with the total winds. Core definition changes between the stages as described in the text.

cumulative mass of entrained air grows by an order of magnitude (Fig. 6a). However, the fractional entrainment rate is quite low during the mature stage (Fig. 6c), in accord with that calculated in simulated supercells by PNM20 with a different method, and indicative that the much greater vertical mass flux within the updraft at this time is less diluted by entrainment. These fractional entrainment rates are an order of magnitude less than those directly calculated for tropical deep convection in low-shear environments by Romps (2010) and Hannah (2017). In the next sections, the specific mechanisms of entrainment, and their influence on dilution, are examined separately during these two stages to understand why the entrainment rates at both stages differ so much from each other, and potentially in their analogs in low-shear (or no shear) environments.

\section{Entrainment and dilution during the developing stage}

\section{a. Entrainment mechanisms}

Vertical profiles of local entrainment rates normalized by the core surface area show increasingly larger values near the cloud tops as the developing stage progresses. By $55 \mathrm{~min}$ (Fig. 7a), a peak in the entrainment rate right below cloud top is evident near $2500-\mathrm{m}$ altitude that ascends in time. As later turrets with thermal circulations near their tops become dominant (Figs. 7b,c), multiple maxima in entrainment occur, and are nearly double the values from the previous turrets. Vertical cross sections at these times show a narrow updraft in the north-south direction (Fig. 8a) with stronger overturning motions from the $P$-type thermal circulation, on the northern (downshear, at this altitude) side. Later and at higher altitude, 

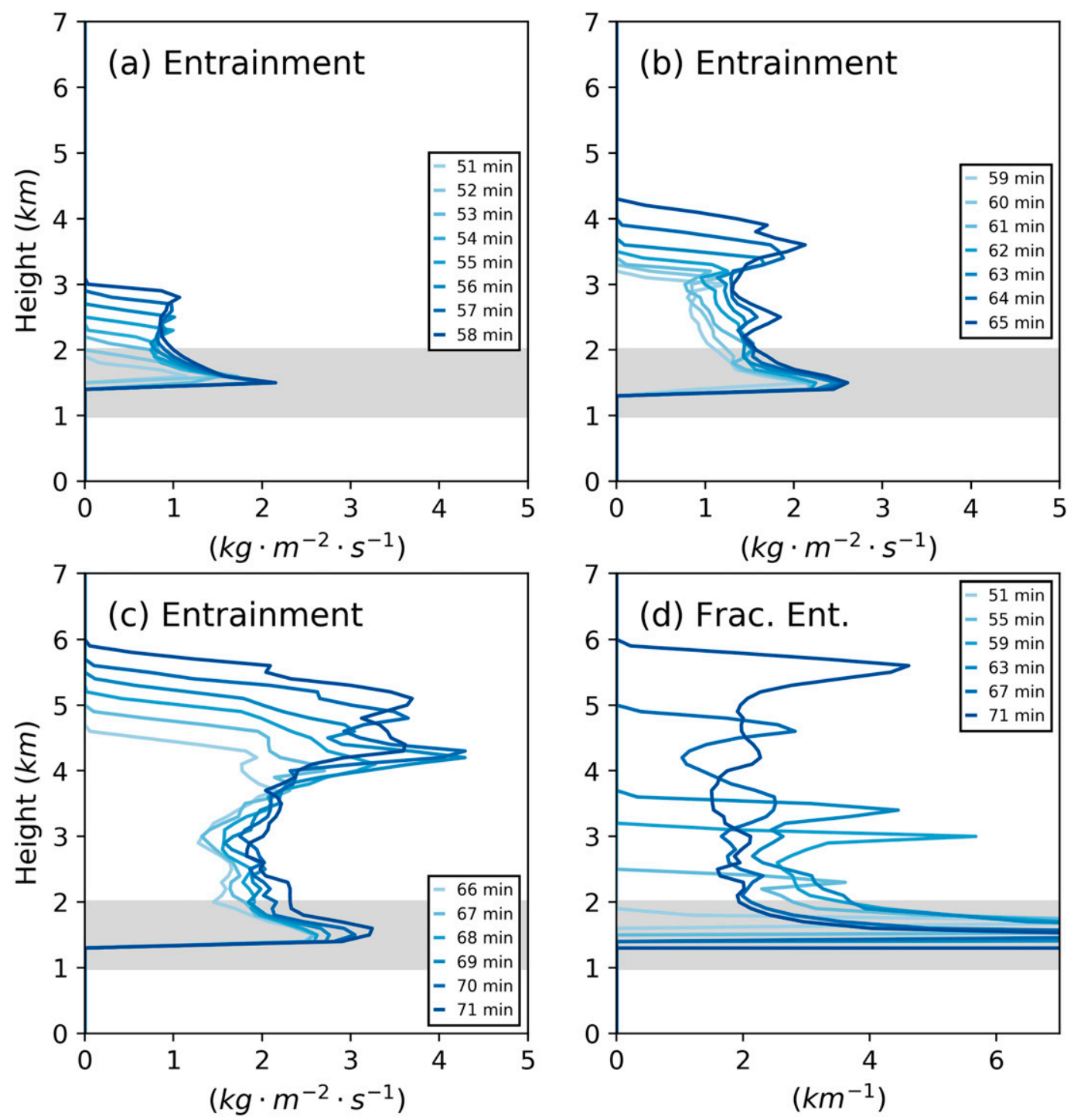

FIG. 7. Vertical profiles of surface area-normalized entrainment rates over the developing stage. Each curve represents 1-min averages for the period ending at the time listed in the legend. (a)-(c) The times of the first, second, and third dominant turrets, respectively. (d) Profiles of fractional entrainment at various times throughout the developing stage. Gray transparent box indicates where values are partly exaggerated by updraft mass flux into the base of the core and thus true entrainment rates are unknown.

the $P$-type thermal circulation on the downshear side (at $5 \mathrm{~km}$, on the east side of Fig. 8b) is even stronger than before, and results in the highest entrainment rates during the developing stage (Fig. 7c), over $4 \mathrm{~kg} \mathrm{~m}^{-2} \mathrm{~s}^{-1}$. For comparison, much lower entrainment rates were calculated by Moser and Lasher-Trapp (2018) using the same method but for more symmetrical thermal circulations within cumuli growing in a low-shear environment; values there never surpassed $1.25 \mathrm{~kg} \mathrm{~m}^{-2} \mathrm{~s}^{-1}$. Entrainment at lower rates also occurs on the upshear side of the core due to the environmental winds impinging upon the core (Fig. 8c); it is relatively weak because the storm-relative winds impart little net horizontal mass flux through the core on that side. Entrainment also occurs on the downshear side of the core
(Fig. 8b), as expected from pressure perturbations on the cloud sides attributable especially to linear and nonlinear dynamic pressure effects, as well as other buoyancy-related effects (e.g., Trapp 2013, chapter 7; Marion and Trapp 2019, their Fig. 14). Fractional entrainment profiles (Fig. 7d) decrease in time (when ignoring the peaks due to the updraft at the base of the cores and near cloud top due to the significant slowing of the upward mass flux there) because the higher entrainment rates at the core surfaces are accompanied by stronger and larger updraft cores.

\section{b. Dilution}

The great impact of entrainment during the developing stage is evident by the dilution of condensate within the three 

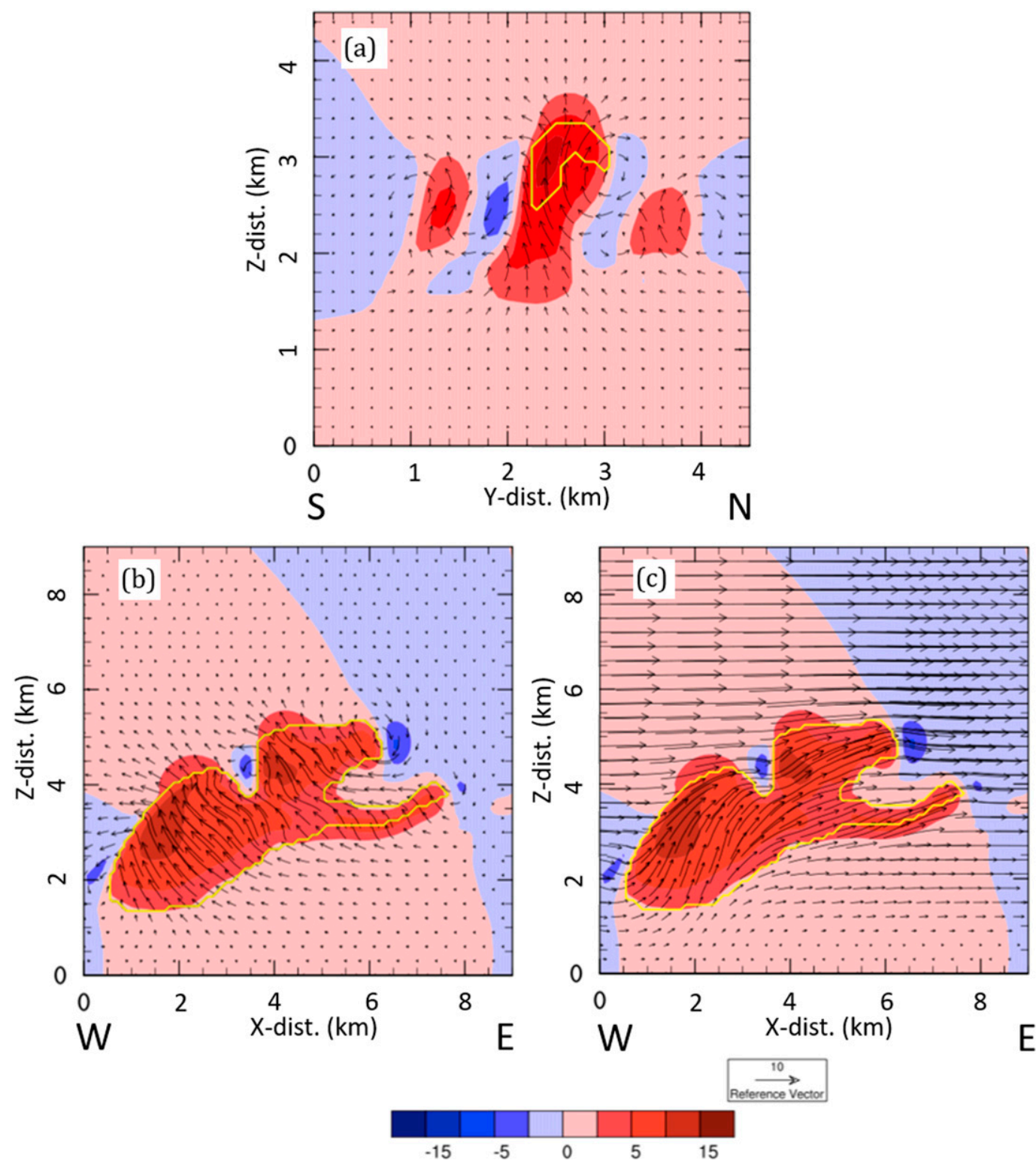

FIG. 8. Zoomed cross sections of multiple turrets during the developing stage, with vertical velocity (shaded) and perturbation wind vectors (arrows) for (a) north-south vertical cross section at 63 min and (b) east-west vertical cross section at $69 \mathrm{~min}$. (c) As in (b), but for total winds overlaid. Cloud core outlined in yellow. Entire cloud depths do not completely lie in the plane of the cross sections.

dominant turrets. Time series (Fig. 9) of maximum liquid water content (LWC), and the corresponding adiabatic liquid water content (ALWC), show that as each turret (with an asymmetric thermal circulation near its top) emerges, it is diluted significantly from its adiabatic value. No regions of undiluted core persist in the first two turrets, and the least diluted parcel near the end of the first turret was only $45 \%$ of the adiabatic value. This dilution is more extreme than estimated from observations of adiabatic parcels in low-shear Hawaiian cumuli by Raga et al. (1990), and also in Florida cumuli where measured liquid water contents were often $80 \%$ or more of the adiabatic values (Blyth et al. 2005). This dilution is also much greater than in cumuli simulated by Moser and Lasher-Trapp (2018) in a lower-shear and less humid environment, where $15 \%$ of the cloud cores contained a liquid water content exceeding $70 \%$ of the adiabatic value. Dilution rates estimated in the first two turrets here, when the $P$ circulations are in the clear air, are approximately $33 \%-56 \%$ greater than the maximum rate calculated in the simulated thermals by Moser and Lasher-Trapp (2017, their Fig. 7), in a drier environment lacking wind shear. The entrainment resulting from the $P$-type thermal circulations in the upper parts (greater than $4 \mathrm{~km}$ altitude) of the turrets shown here are highly negatively correlated $(R=-0.78)$ with the percent change in the median core liquid water mixing ratio 


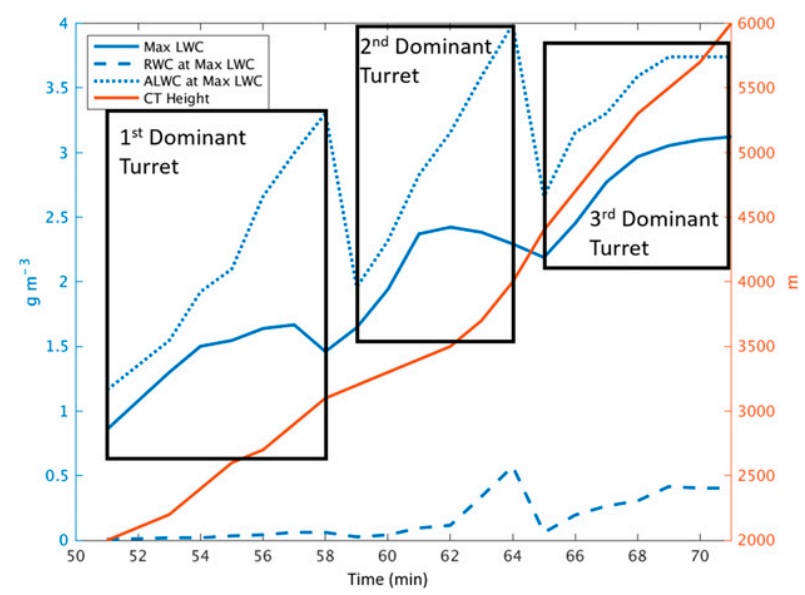

FIG. 9. Time series during the developing stage of the maximum LWC anywhere in the domain, the maximum rainwater content (RWC) at the location of the maximum LWC, the adiabatic liquid water content (ALWC) at the height corresponding to the max LWC, and cloud-top (CT) height. Water contents is in $\mathrm{g} \mathrm{m}^{-3}$ on the left axis, and CT height is in $\mathrm{m}$ on the right axis. Large black rectangles denote time periods when each turret was dominant.

(i.e., the dilution of cloud water and rain) at the same height level within the following two minutes. This strong correlation results as these asymmetrical overturning eddies emerge into the environmental air apart from other turrets.

The second and third turrets dilute less than the earlier ones, however, as they partially rise through and entrain cloudy remnants (as also found by Moser and Lasher-Trapp 2017). Older turrets are also sometimes shielded by new turrets developing upshear, as determined by visual inspection (Engelsen 2018). The third turret shown in Fig. 9 contains nearly undiluted regions, as the rainwater content (RWC) summed with the LWC value at that same location is nearly equivalent to the ALWC value at that height. Although not shown in detail, the continuous ascent of the cloud-top height shown in Fig. 9 is also driven by the replenishment of buoyancy by later, less diluted turrets. Thus, even though the quantified entrainment is greatest at the end of the developing stage, as later turrets merge with earlier ones the core volume suddenly increases, and the fractional entrainment decreases drastically, indicative of less dilution and allowing substantial cloud and rainwater to exist by the end of the developing stage. At that time, the first surface precipitation occurs (Fig. 6), unburdening the updraft of some of its mass, and initiating the process that will produce the gust front and enhanced lifting of air into the updraft.

\section{Entrainment and dilution during the mature stage}

\section{a. Entrainment mechanisms}

Vertical profiles of entrainment during the mature stage (Fig. 10) show that the storm core entrains air throughout much of its depth but with transient maxima. As opposed to the developing stage, the peak in the entrainment profile near the storm base extends to a much higher altitude, up to $4 \mathrm{~km}$. This peak still includes the vertical mass flux beneath the quasihorizontal base of the core (and thus is not considered entrainment), but also contains a contribution from the downshear environmental air streaming into the core at levels above the storm base. This entrained air has lower temperatures and is drier than air ascending in the updraft from beneath the storm base. It will be referred to here as the storm-relative airstream, as it is well known to depend upon the storm motion (e.g., Browning 1964) and can increase as the storm motion increases with increasing vertical wind shear (e.g., Warren et al. 2017). It is used here to clearly separate it from the air originating beneath the LCL that moves vertically into the base of the core. The fractional entrainment (Fig. 10d) above $4 \mathrm{~km}$ altitude that neglects the storm-relative airstream tends to be near $0.25 \mathrm{~km}^{-1}, 8$ times smaller than that of the developing stage, indicating that much less of the core at mid- to upper levels is diluted by entrainment at this time.

A time-height contour plot of net entrainment (Fig. 11) illustrates general entrainment and detrainment patterns over the entire mature stage. Entrainment generally dominates below approximately 8 -km altitude, and detrainment dominates above this height. However, notable in this figure are periodic streaks of net entrainment (blue streaks) originating above $5 \mathrm{~km}$ and ascending in time, sometimes up to $10 \mathrm{~km}$. These diagonal streaks are collocated with transient features on the core edge, clearly evident in a three-dimensional rendering of the core shaded by the winds entering and leaving the core edge (Fig. 12). These "ribbons," i.e., couplets of entrainment and detrainment due to an elongated overturning circulation, range in diameter from 1 to $2.5 \mathrm{~km}$ (while the diameter of the core tends to be $8-10 \mathrm{~km}$ ). It is possible that the striations sometimes visible on a rotating supercell updraft are indicative of these features. The ribbons are no longer evident above $10 \mathrm{~km}$, where detrainment within the anvil becomes dominant. The broader area of entrainment at the base of the core on the SE side in Fig. 12 is indicative of the storm-relative airstream, lacking overturning motions.

The ribbon-like features on the core surface are regions of horizontal vorticity (Fig. 13a) that entrain air below and detrain air aloft, similar to an overturning thermal circulation. They begin on the west side of the core and strengthen as they wrap cyclonically around the southern side. The ribbons are hypothesized to be generated through the horizontal buoyancy gradient within the updraft, enhanced through (horizontal) vortex stretching where the cyclonic circulation of the updraft works in tandem with the environmental winds. A simplified version of the equation governing $x$-component vorticity lends support to this generation mechanism:

$$
\frac{\partial \omega_{x}}{\partial t} \approx \omega_{x} \frac{\partial u}{\partial x}+\frac{\partial B}{\partial y},
$$

where $\omega_{x}$ denotes horizontal vorticity along the $x$ axis, the first term on the right-hand side is stretching of this horizontal vorticity in the $x$ direction by the gradient of $u$, the $x$ component of the horizontal wind, and the second term is the 

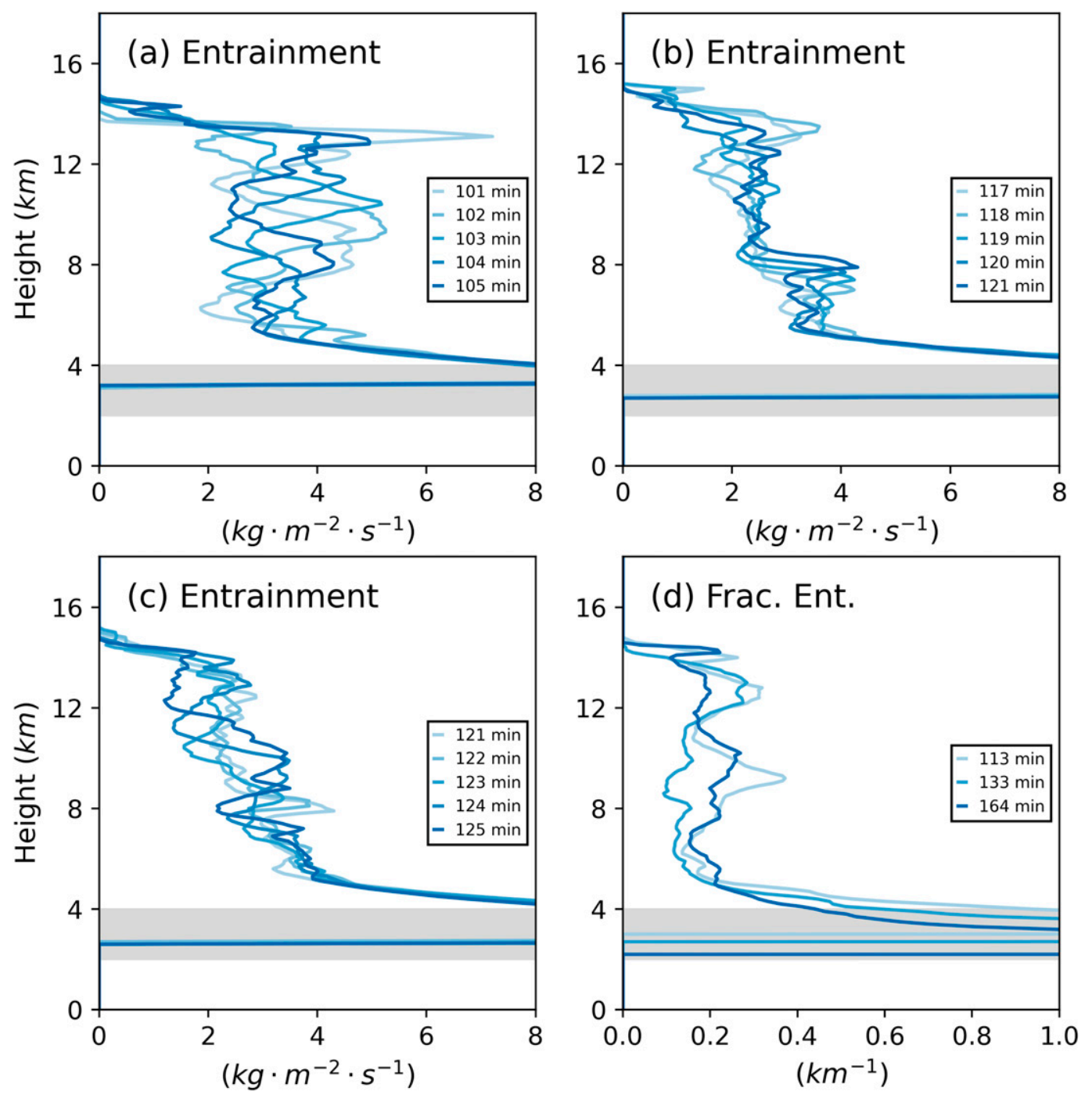

FIG. 10. As in Fig. 7, but for values at various times during the mature stage.

$y$-direction gradient in buoyancy $B$. [The effects of advection, tilting, and friction are neglected in Eq. (3).] In the simulation, the core updraft (Fig. 13a) has an inwarddirected buoyancy gradient $(\partial B / \partial y)$ that acts to generate horizontal vorticity, as indicated in a simplified schematic for reference (Fig. 13b). In the absence of all winds, this buoyancy gradient term alone would act to generate a ring of horizontal vorticity around the buoyant updraft, as in a symmetrical thermal. However, the storm-relative environmental winds at midlevels act in tandem with the cyclonic circulation in the southwest quadrant of the rotating updraft (e.g., where $\partial u / \partial x$ is positive in Fig. 13b), stretching the horizontal vorticity, amplifying the overturning associated with the entraining ribbons, as shown in Fig. 13a. In contrast, the cyclonic circulation works against the stormrelative environmental flow over the northwest quadrant of the core (Fig. 13b), contracting the horizontal vorticity there and thus hampering the overturning, as indicated by the lack of horizontal vorticity there (Fig. 13a). On the north side of the core, some entrainment does occur, but mainly by disorganized, small-scale (less than $\sim 1 \mathrm{~km}$ ) eddies on the northwest side. The east side of the core lacks any indication of overturning small-scale eddies, hypothesized to result

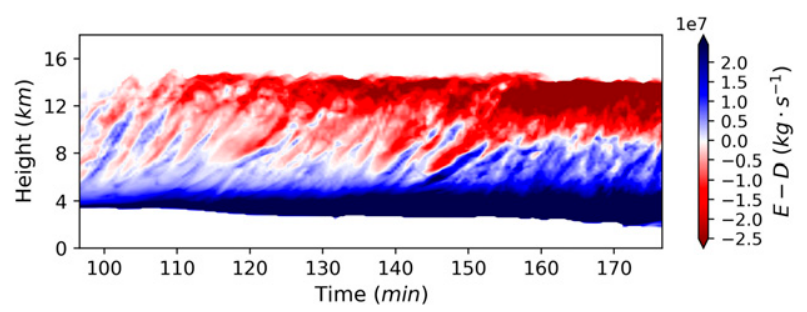

FIG. 11. Time-height diagram of values of net entrainment (blue) and net detrainment (red) during the mature stage averaged over 24-s periods. 


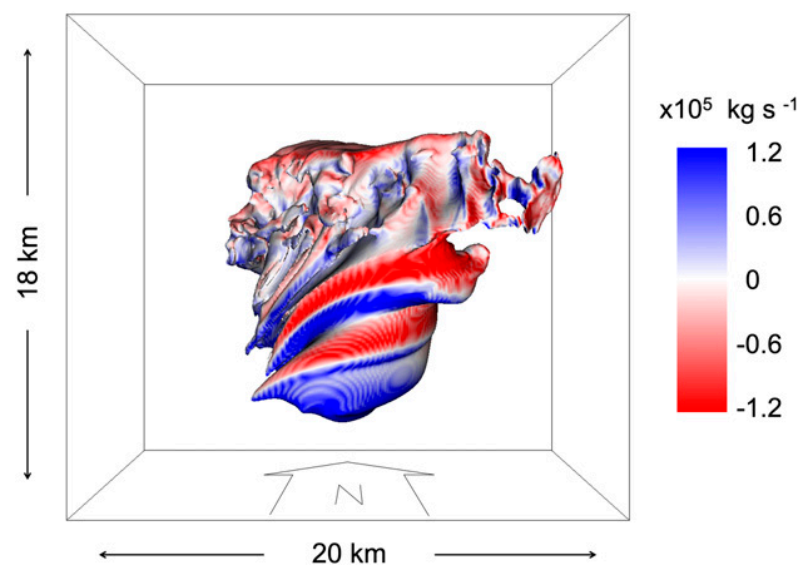

FIG. 12. Three-dimensional rendering of entrainment (blue) and detrainment (red) rates on surface of the cyclonically rotating core at $129 \mathrm{~min}$, as viewed from the south while storm moves eastward. Depth of box (into the page) is $20 \mathrm{~km}$.

from the weak horizontal buoyancy gradient and environmental winds there (Fig. 13a).

The overturning circulations in the ribbons are strongest from 115 to $155 \mathrm{~min}$. After this time, they visually appear to break up into disorganized, small-scale eddies for the rest of the analysis period. This breakup may be influenced by two factors. The dilution at the core edge by the ribbons themselves (to be shown in the next section) may weaken the buoyancy gradient at the core edge. In addition, the surface cold pool from the precipitating storm surges forward at $155 \mathrm{~min}$, creating a small directional change (approximately $10^{\circ}$ toward the southeast) in the storm motion. This change may weaken the storm-relative environmental winds that were contributing to the ribbon circulations by vortex stretching.

The amount of entrainment into the core attributable to different mechanisms, during the time of maximum visual prominence of ribbons (115-155 $\mathrm{min})$, can be roughly estimated using the entrainment algorithm and masking certain regions of the core edge. Neglecting any entrainment occurring in the turbulent anvil region from the total, the vorticity ribbons on the southern half of the core between 4 and $9 \mathrm{~km}$ contribute approximately $30 \%$ to the total entrainment into the core. On the upshear side of the core, entrainment from small-scale overturning eddies assisted by the impinging storm-relative environmental winds contributes an additional $25 \%$. Engulfment of air by expansion of the core in all directions $[d V / d t$ in Eq. (3)], but mainly in the downshear direction, also contributes $20 \%$. The storm-relative airstream between 2 - and $4-\mathrm{km}$ altitudes contributes another $20 \%$ to the total entrainment.

\section{b. Dilution}

Passive tracers are used to diagnose the dilution in the mature stage as described in section $2 \mathrm{~d}$. The bLCL tracer (distributed uniformly from the surface to the height of the LCL; Figs. 14 a,b), primarily entering the core of the storm from the south and east, mainly occupies the southern and western

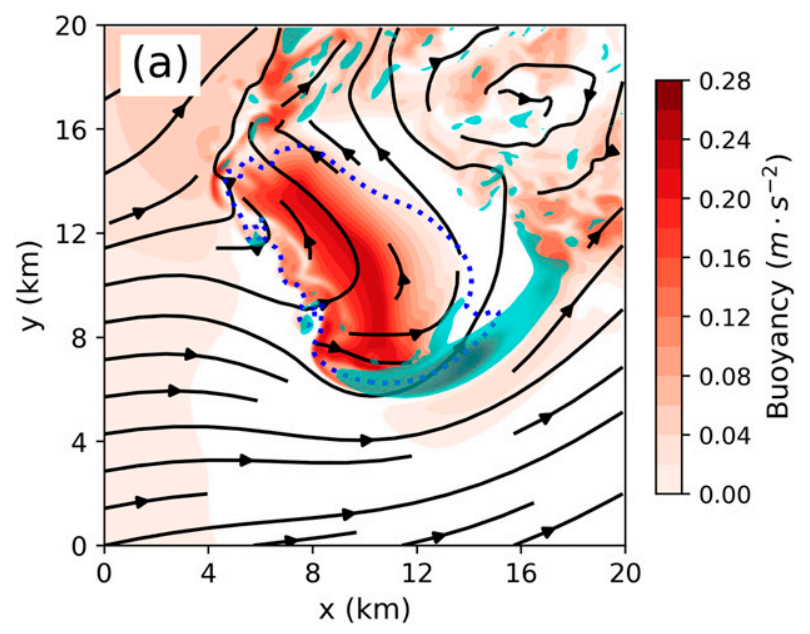

(b)

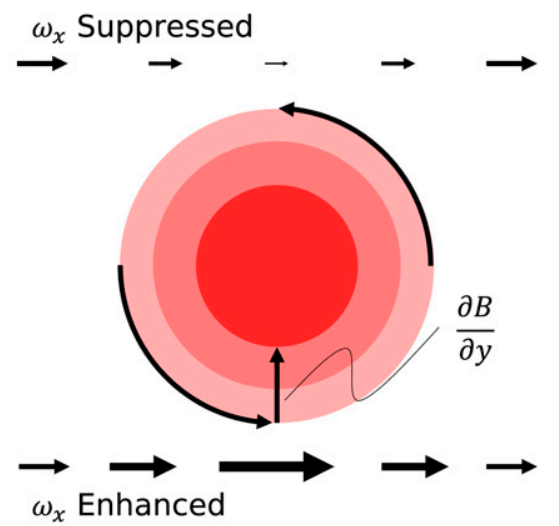

FIG. 13. (a) Horizontal cross section of storm updraft at 6-km altitude, corresponding to the time shown in Fig. 12. Buoyancy (shaded in red color scale), core boundary (dashed dark blue contour), positive horizontal vorticity exceeding $0.05 \mathrm{~s}^{-1}$ (teal shading), and horizontal streamlines (black) of storm-relative environmental winds as indicated. (b) Simplified schematic of (a), using the terms from Eq. (3) as discussed in the text.

regions of the core (red outline). Dilution by the overturning circulations within the ribbons is evident on both the western (Fig. 14a) and southern (Fig. 14c) sides, but their limited "reach" into this air within the core is also clear. As a result, regions of undiluted bLCL air (within white contour in Fig. 14, having a tracer concentration exceeding 0.99) extend the entire depth of the $20 \mathrm{~m} \mathrm{~s}^{-1}$ core, in accord with observations of undiluted parcels in supercell updrafts in the literature, and with calculations by Nowotarski et al. (2020) using tracer analysis for a simulated storm in this same environment.

All of the mechanisms of entrainment combined will dilute some of the bLCL air ingested by the updraft through the storm base. Such dilution is of primary interest, because the bLCL air in this sounding is the warmest and contains the most water vapor, and thus contributes the most to the updraft buoyancy and precipitation formation. During the mature stage, undiluted bLCL air is nearly always found within the 

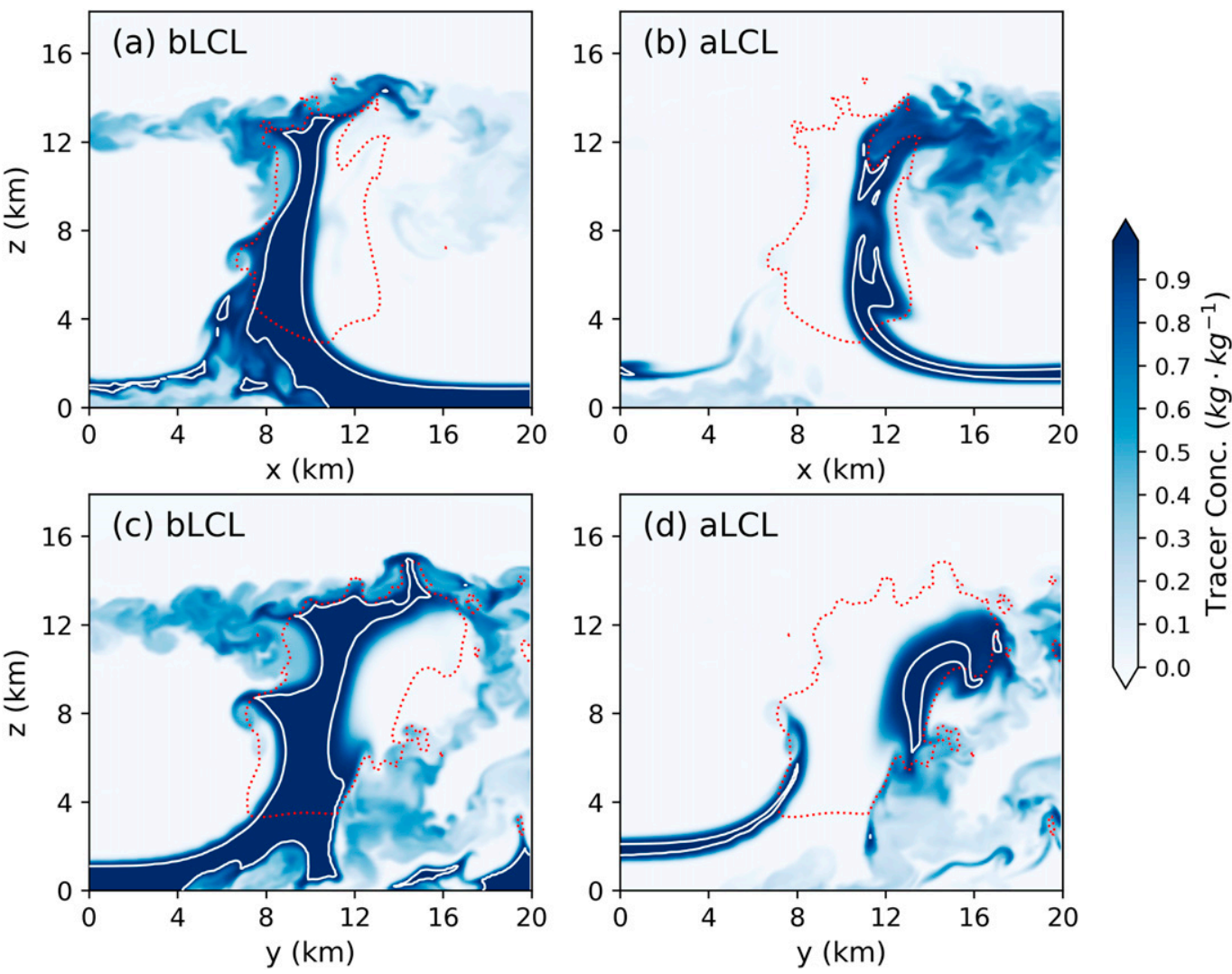

FIG. 14. (a),(b) East-west and (c),(d) north-south vertical cross sections at 120 min of (left) bLCL tracer mixing ratio and (right) aLCL tracer mixing ratio as described in text. White contour denotes values exceeding 0.99 (undiluted tracer), and dashed red contour denotes boundary of $20 \mathrm{~m} \mathrm{~s}^{-1}$ updraft.

storm core (Fig. 15a) ranging from nearly $0 \%$ to over $50 \%$ of the core volume at times; periods of greater fractional entrainment correspond to greater dilution of this bLCL air (Fig. 15b). When averaged over the times and depths shown in Fig. 15a, approximately only $20 \%$ of the mature, rotating thunderstorm core contains undiluted air from beneath the LCL.

Regions of the core that appear to be devoid of bLCL air in Figs. $14 \mathrm{a}$ and $14 \mathrm{~b}$ are instead dominated by aLCL air (entrained within $1 \mathrm{~km}$ above the LCL) by the storm-relative airstream on the downshear (eastern: Fig. 14b; southern: Fig. 14d) sides. Additional tracers placed at higher altitudes (not shown) corroborate that air is introduced by the stormrelative airstream up to $4 \mathrm{~km}$ above the storm base, in accord with a trajectory analysis by Nowotarski et al. (2011) for the same environment. This entrained air appears to contribute to the expansion of the core width at midlevels; it occupies different space within the core than the bLCL air. This aLCL air still contains significant amounts of buoyancy, and water vapor (especially in the humid environment of this sounding), and thus is not so "erosive" as air entrained at higher altitudes. The air entrained by the storm-relative airstream still condenses upon ascent into the core and can contribute to precipitation formation (examined by model condensation rates), as also noted for example in cumulus congestus by Langhans et al. (2015) and supercells by Warren et al. (2017). The entrained aLCL air itself can be diluted by the overturning ribbons, as shown on the southern (left) side of the core (Fig. 14d) and verified in 3D animations, but undiluted aLCL air can often also be found extending to the top of the core.
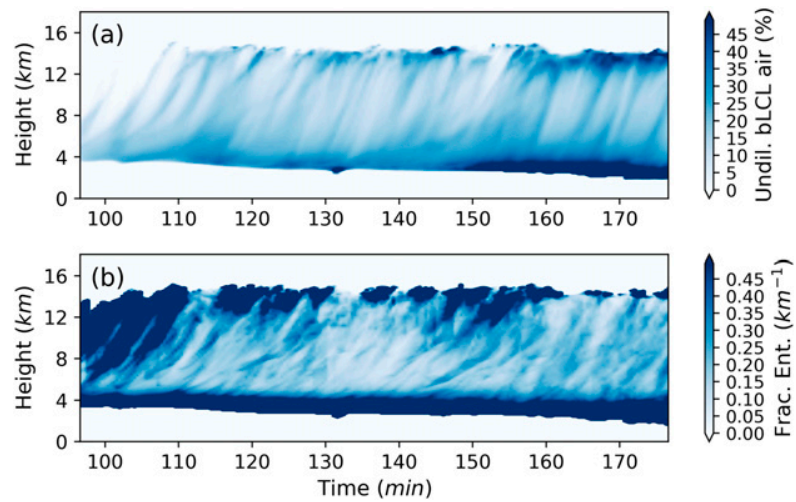

FIG. 15. Time-height diagrams during the mature stage of (a) percentage of total core volume containing undiluted subcloud (bLCL) air and (b) fractional entrainment. Areas shaded in darkest blue denote values greater than the maximum value listed in each legend. 


\section{Summary and discussion}

This study sought to identify specific mechanisms of entrainment and evaluate their dilution in the developing and mature stages of a numerically simulated supercell thunderstorm produced in an environment with strong vertical wind shear. The main findings were as follows:

- Maximum entrainment rates increased exponentially during the developing stage of the storm, primarily in the upper regions of ascending cloud turrets that contained an asymmetrical thermal circulation where overturning eddies are stronger on the downshear side. Local entrainment rates were up to 4 times as large as published values calculated with the same method in cumuli in a low-shear environment. Fractional entrainment rates were as much as twice as large as those published in the literature in cumulus congestus growing in environments lacking shear.

- Dilution of air parcels within the cores during the developing stage was linked to their asymmetric thermal circulations and was effective in preventing the persistence of undiluted parcels in the earliest turrets. This dilution was more extreme than noted in past observational and modeling studies of cumuli in low-shear environments. It was estimated that the depletion of condensate was $33 \%-50 \%$ more effective than that calculated in a cumulus congestus in an environment lacking shear.

- Despite the detrimental effects of the high entrainment rates during the developing stage, the nascent storm continued to develop by the replenishment of buoyancy and moisture from subsequent cloud turrets somewhat shielded from the erosive effects of entrainment by ascending through the remnants of their predecessors, and eventually merging, as shown in past studies in environments lacking shear.

- In the mature stage of the supercell, entrainment rates were equivalent to, or exceeded, those in the developing stage, while fractional entrainment rates were far less, as found in published studies. The greatest local entrainment rates resulted from a mechanism first identified here: "ribbons", of horizontal vorticity that translate vertically and counterclockwise with the air at the rotating core edge. The ribbons occurred on the side of the core where the cyclonic rotation of the updraft worked in unison with the direction of the storm-relative environmental winds; it was hypothesized that vorticity stretching amplifies the vorticity in the ribbons (and thus the overturning and entrainment) there.

- The narrow overturning circulations of the entraining ribbons diluted air at the core boundaries but were ineffective in diluting the interior region of the much wider storm core, consistent with fractional entrainment trends found in past studies. Passive tracers placed into the lower levels of the simulation domain showed that on average only $20 \%$ of the storm core contained undiluted air from beneath the lifting condensation level during the 80-min period examined. Some entrained air from above the storm base also persisted undiluted to the top of the core and contained sufficient moisture to assist precipitation production.
This study has identified several entrainment mechanisms acting in a supercell thunderstorm as a result of its high-shear environment, but the most important appear to be those attributed to transient, overturning eddy-like structures. The vertical wind shear enhanced entrainment and dilution during the developing stage, by promoting an asymmetrical thermal circulation that increased its effectiveness relative to an environment having less or no shear. The entraining ribbons on the edge of the rotating updraft during the mature stage appear to be a similar manifestation: an elongated asymmetrical thermal circulation resulting from buoyancy gradients at the core edge but strengthened by the winds of the rotating updraft along its axis. While the dilution effects here are consistent with the findings of PNM20, they assumed that supercells entrain in a continuous manner similar to that of plumes, while the most effective entrainment mechanisms found here are transient and discrete like thermals.

The dependency of these results upon a single simulation is certainly the most severe limitation of this study. Further study in environments with different amounts of vertical wind shear is required to evaluate more generally the dependency of the entrainment and dilution of asymmetrical thermal circulations upon the strength of the shear, as well as the source, transience, frequency, and dilutive effects of the vorticity ribbons in mature supercells. Further study considering environments with different humidity profiles, and particularly drier ones, is also needed. Such studies will undoubtedly elucidate trends that were not clear from the single simulation used here.

Acknowledgments. Comments from Dr. John Peters and two anonymous reviewers greatly improved this manuscript. This study used the open-source CM1 model written and maintained by Dr. George Bryan of the National Center for Atmospheric Research (funded by the National Science Foundation), and the NSSL microphysical parameterization within CM1 written and maintained by Dr. Ted Mansell of the National Severe Storms Laboratory (funded by the National Oceanic and Atmospheric Administration). This study was supported by an award from the National Science Foundation, AGS17-25190, and also benefitted from the Blue Waters sustained-petascale computing project, supported by the National Science Foundation (Awards OCI-0725070 and ACI1238993) and the state of Illinois.

Data availability statement. The model code and initialization conditions used to create the numerical simulations for this study can be made available upon request.

\section{REFERENCES}

American Meteorological Society, 2020: Entrainment. Glossary of Meteorology, http://glossary.ametsoc.org/wiki/Entrainment.

Arakawa, A., 2004: The cumulus parameterization problem: Past, present, and future. J. Climate, 17, 2493-2525, https://doi.org/ 10.1175/1520-0442(2004)017<2493:RATCPP > 2.0.CO;2.

Bluestein, H. B., E. W. McCaul Jr., G. P. Byrd, and G. R. Woodall, 1988: Mobile sounding observations of a tornadic storm near the dryline: The Canadian, Texas storm of 7 May 1986. 
Mon. Wea. Rev., 116, 1790-1804, https://doi.org/10.1175/15200493(1988)116<1790:MSOOAT > 2.0.CO;2.

Blyth, A. M., 1993: Entrainment in cumulus clouds. J. Appl. Meteor., 32, 626-641, https://doi.org/10.1175/1520-0450(1993) $032<0626$ :EICC $>2.0 . \mathrm{CO} ; 2$.

— tion in New Mexican summertime cumulus clouds. Quart. J. Roy. Meteor. Soc., 119, 91-120, https://doi.org/10.1002/ qj.49711950905.

- , S. G. Lasher-Trapp, and W. A. Cooper, 2005: A study of thermals in cumulus clouds. Quart. J. Roy. Meteor. Soc., 131, 1171-1190, https://doi.org/10.1256/qj.03.180.

Boe, B. A., and Coauthors, 1992: The North Dakota Thunderstorm Project: A cooperative study of High Plains thunderstorms. Bull. Amer. Meteor. Soc., 73, 145-160, https:// doi.org/10.1175/1520-0477(1992)073<0145:TNDTPA >2.0.CO;2.

Browning, K. A., 1964: Airflow and precipitation trajectories within severe local storms which travel to the right of the winds. J. Atmos. Sci., 21, 634-639, https://doi.org/10.1175/15200469(1964)021<0634:AAPTWS>2.0.CO;2.

Bryan, G. H., and J. M. Fritsch, 2002: A benchmark simulation for moist nonhydrostatic numerical models. Mon. Wea. Rev., 130, 2917-2928, https://doi.org/10.1175/1520-0493(2002)130<2917: ABSFMN $>2.0 . \mathrm{CO} ; 2$.

_ , and H. Morrison, 2012: Sensitivity of a simulated squall line to horizontal resolution and parameterization of microphysics. Mon. Wea. Rev., 140, 202-225, https://doi.org/10.1175/MWRD-11-00046.1.

— J. C. Wyngaard, and J. M. Fritsch, 2003: Resolution requirements for the simulation of deep moist convection. Mon. Wea. Rev., 131, 2394-2416, https://doi.org/10.1175/ 1520-0493(2003)131<2394:RRFTSO > 2.0.CO;2.

Carpenter, R. L., K. K. Droegemeier, and A. M. Blyth, 1998: Entrainment and detrainment in numerically simulated cumulus congestus clouds. Part I: General results. J. Atmos. Sci., 55, 3417-3432, https://doi.org/10.1175/1520-0469(1998) $055<3417$ :EADINS $>2.0 . \mathrm{CO} ; 2$.

Dawe, J. T., and P. H. Austin, 2011a: The influence of the cloud shell on tracer budget measurements of LES cloud entrainment. J. Atmos. Sci., 68, 2909-2920, https://doi.org/10.1175/2011JAS3658.1.

— and - 2011b: Interpolation of LES cloud surfaces for use in direct calculations of entrainment and detrainment. Mon. Wea. Rev., 139, 444-456, https://doi.org/10.1175/2010MWR3473.1.

Deardorff, J. W., 1980: Stratocumulus-capped mixed layers derived from a three-dimensional model. Bound.-Layer Meteor., 18, 495-527, https://doi.org/10.1007/BF00119502.

de Rooy, W. C., and Coauthors, 2013: Entrainment and detrainment in cumulus convection: An overview. Quart. J. Roy. Meteor. Soc., 139, 1-19, https://doi.org/10.1002/qj.1959.

Engelsen, B. N., 2018: The effects of entrainment in the developing and rotating stages of supercell thunderstorms. M.S. thesis, Dept. of Atmospheric Sciences, University of Illinois at Urbana-Champaign, 59 pp.

Gerber, H. E., G. M. Frick, J. B. Jensen, and J. G. Hudson, 2008: Entrainment, mixing, and microphysics in trade-wind cumulus. J. Meteor. Soc. Japan, 86A, 87-106, https://doi.org/10.2151/ jmsj.86A.87.

Hannah, W. M., 2017: Entrainment versus dilution in tropical deep convection. J. Atmos. Sci., 74, 3725-3747, https://doi.org/ 10.1175/JAS-D-16-0169.1.

Hernandez-Deckers, D., and S. C. Sherwood, 2016: A numerical investigation of cumulus thermals. J. Atmos. Sci., 73, 41174136, https://doi.org/10.1175/JAS-D-15-0385.1.
— , and - 2018: On the role of entrainment in the fate of cumulus thermals. J. Atmos. Sci., 75, 3911-3924, https:// doi.org/10.1175/JAS-D-18-0077.1.

Heymsfield, A. J., P. N. Johnson, and J. E. Dye, 1978: Observations of moist adiabatic ascent in northeast Colorado cumulus congestus clouds. J. Atmos. Sci., 35, 1689-1703, https://doi.org/10.1175/1520-0469(1978)035<1689: OOMAAI $>2.0 . \mathrm{CO} ; 2$.

Kirkpatrick, C., E. W. Mc Caul Jr., and C. Cohen, 2009: Variability of updraft and downdraft characteristics in a large parameter space study of convective storms. Mon. Wea. Rev., 137, 15501561, https://doi.org/10.1175/2008MWR2703.1.

Kirshbaum, D. J., 2011: Cloud-resolving simulations of deep convection over a heated mountain. J. Atmos. Sci., 68, 361-378, https://doi.org/10.1175/2010JAS3642.1.

Kitchen, M., and S. J. Caughey, 1981: Tethered-balloon observations of the structure of small cumulus clouds. Quart. J. Roy. Meteor. Soc., 107, 853-874, https://doi.org/10.1002/qj.49710745407.

Klaassen, G. P., and T. L. Clark, 1985: Dynamics of the cloudenvironment interface and entrainment in small cumuli: Twodimensional simulations in the absence of ambient shear. J. Atmos. Sci., 42, 2621-2642, https://doi.org/10.1175/15200469(1985)042<2621:DOTCEI >2.0.CO;2.

Klemp, J. B., 1987: Dynamics of tornadic thunderstorms. Annu. Rev. Fluid Mech., 19, 369-402, https://doi.org/ 10.1146/annurev.fl.19.010187.002101.

— dimensional convective storm dynamics. J. Atmos. Sci., 35, 1070-1096, https://doi.org/10.1175/1520-0469(1978)035<1070: TSOTDC $>2.0 . C O ; 2$.

Langhans, W., K. Yeo, and D. M. Romps, 2015: Lagrangian investigation of the precipitation efficiency of convective clouds. J. Atmos. Sci., 72, 1045-1062, https://doi.org/10.1175/ JAS-D-14-0159.1.

Lebo, Z. J., and H. Morrison, 2015: Effects of horizontal and vertical grid spacing on mixing in simulated squall lines and implications for convective strength and structure. Mon. Wea. Rev., 143, 4355-4375, https://doi.org/10.1175/MWR-D-15-0154.1.

Lilly, D. K., 1986: The structure, energetics and propagation of rotating convective storms. Part I: Energy exchange with the mean flow. J. Atmos. Sci., 43, 126-140, https://doi.org/10.1175/ 1520-0469(1986)043<0113:TSEAPO>2.0.CO;2.

Loftus, A. M., D. B. Weber, and C. A. Doswell III, 2008: Parameterized mesoscale forcing mechanisms for initiating numerically simulated isolated multicellular convection. Mon. Wea. Rev., 136, 2408-2421, https://doi.org/10.1175/ 2007MWR2133.1.

Ludlam, F. H., 1952: The production of showers by the growth of ice particles. Quart. J. Roy. Meteor. Soc., 78, 543-553, https:// doi.org/10.1002/qj.49707833805.

Malkus, J. S., 1949: Effects of wind shear on some aspects of convection. Eos, Trans. Amer. Geophys. Union, 30, 19-25, https:// doi.org/10.1029/TR030i001p00019.

Mansell, E. R., and C. L. Ziegler, 2013: Aerosol effects on simulated storm electrification and precipitation in a two-moment bulk microphysics model. J. Atmos. Sci., 70, 2032-2050, https:// doi.org/10.1175/JAS-D-12-0264.1.

—_ - _ and E. C. Bruning, 2010: Simulated electrification of a small thunderstorm with two-moment bulk microphysics. J. Atmos. Sci., 67, 171-194, https://doi.org/10.1175/ 2009JAS2965.1.

Marion, G. R., and R. J. Trapp, 2019: The dynamical coupling of convective updrafts, downdrafts, and cold pools in simulated 
supercell thunderstorms. J. Geophys. Res. Atmos., 124, 664683, https://doi.org/10.1029/2018JD029055.

Mason, B. J., and P. R. Jonas, 1974: The evolution of droplet spectra and large droplets by condensation in cumulus clouds. Quart. J. Roy. Meteor. Soc., 100, 23-38, https://doi.org/10.1002/ qj. 49710042304.

Morrison, H., and J. M. Peters, 2018: Theoretical expressions for the ascent rate of moist deep convective thermals. J. Atmos. Sci., 75, 1699-1719, https://doi.org/10.1175/JAS-D-17-0295.1.

Moser, D. H., and S. Lasher-Trapp, 2017: The influence of successive thermals on entrainment and dilution in a simulated cumulus congestus. J. Atmos. Sci., 74, 375-392, https://doi.org/ 10.1175/JAS-D-16-0144.1.

- and - 2018: Cloud-spacing effects upon entrainment and rainfall along a convective line. J. Appl. Meteor. Climatol., 57, 1865-1882, https://doi.org/10.1175/JAMC-D-17-0363.1.

Musil, D. J., A. J. Heymsfield, and P. L. Smith, 1986: Microphysical characteristics of a well-developed weak echo region in a High Plains supercell thunderstorm. J. Climate Appl. Meteor., 25, 1037-1051, https://doi.org/10.1175/1520-0450(1986)025<1037: MCOAWD $>2.0 . \mathrm{CO} ; 2$.

Naylor, J., and M. S. Gilmore, 2012: Convective initiation in an idealized cloud model using an updraft nudging technique. Mon. Wea. Rev., 140, 3699-3705, https://doi.org/10.1175/ MWR-D-12-00163.1.

,,-- R. L. Thompson, R. Edwards, and R. B. Wilhelmson, 2012: Comparison of objective supercell identification techniques using an idealized cloud model. Mon. Wea. Rev., 140, 2090-2102, https://doi.org/10.1175/MWR-D-11-00209.1.

Nowotarski, C. J., P. M. Markowski, and Y. P. Richardson, 2011: The characteristics of numerically simulated supercell storms situated over statically stable boundary layers. Mon. Wea. Rev., 139, 3139-3162, https://doi.org/10.1175/MWR-D-10-05087.1.

_ J. M. Peters, and J. P. Mulholland, 2020: Evaluating the effective inflow layer of simulated supercell updrafts. Mon. Wea. Rev., 148, 3507-3532, https://doi.org/10.1175/MWR-D20-0013.1.

Ovtchinnikov, M., and Y. L. Kogan, 2000: An investigation of ice production mechanisms in small cumuliform clouds using a 3D model with explicit microphysics. Part I: Model description. J. Atmos. Sci., 57, 2989-3003, https://doi.org/ 10.1175/1520-0469(2000)057<2989:AIOIPM>2.0.CO;2.

Petch, J. C., 2006: Sensitivity studies of developing convection in a cloud-resolving model. Quart. J. Roy. Meteor. Soc., 132, 345358, https://doi.org/10.1256/qj.05.71.

Peters, J. M., C. J. Nowotarski, and H. Morrison, 2019a: The role of vertical wind shear in modulating maximum supercell updraft velocities. J. Atmos. Sci., 76, 3169-3189, https://doi.org/10.1175/ JAS-D-19-0096.1.

_ - W. Hannah, and H. Morrison, 2019b: The influence of vertical wind shear on moist thermals. J. Atmos. Sci., 76, 16451659, https://doi.org/10.1175/JAS-D-18-0296.1.

_ C. J. Nowotarski, and G. L. Mullendore, 2020a: Are supercells resistant to entrainment because of their rotation?
J. Atmos. Sci., 77, 1475-1495, https://doi.org/10.1175/JAS-D19-0316.1.

__, __, J. P. Mulholland, and R. L. Thompson, 2020b: The influences of effective inflow layer streamwise vorticity and storm-relative flow on supercell updraft properties. J. Atmos. Sci., 77, 3033-3057, https://doi.org/10.1175/JASD-19-0355.1.

Raga, G. B., J. B. Jensen, and M. B. Baker, 1990: Characteristics of cumulus band clouds off the coast of Hawaii. J. Atmos. Sci., 47, 338-356, https://doi.org/10.1175/1520-0469(1990) 047<0338:COCBCO > 2.0.CO;2.

Roesner, S., A. I. Flossmann, and H. R. Pruppacher, 1990: The effect on the evolution of the drop spectrum in clouds of the preconditioning of air by successive convective elements. Quart. J. Roy. Meteor. Soc., 116, 1389-1403, https://doi.org/ 10.1002/qj.49711649607.

Romps, D. M., 2010: A direct measure of entrainment. J. Atmos. Sci., 67, 1908-1927, https://doi.org/10.1175/2010JAS3371.1.

_- and Z. Kuang, 2010: Do undiluted convective plumes exist in the upper tropical troposphere? J. Atmos. Sci., 67, 468-484, https://doi.org/10.1175/2009JAS3184.1.

Simpson, J., R. H. Simpson, D. A. Andrews, and M. A. Eaton, 1965: Experimental cumulus dynamics. Rev. Geophys., 3, 387-431, https://doi.org/10.1029/RG003i003p00387.

Thompson, R. L., C. M. Mead, and R. Edwards, 2007: Effective storm-relative helicity and bulk shear in supercell thunderstorm environments. Wea. Forecasting, 22, 102-115, https:// doi.org/10.1175/WAF969.1.

Trapp, R. J., 2013: Mesoscale-Convective Processes in the Atmosphere. Cambridge University Press, 377 pp.

— G. R. Marion, and S. W. Nesbitt, 2017: The regulation of tornado intensity by updraft width. J. Atmos. Sci., 74, 41994211, https://doi.org/10.1175/JAS-D-16-0331.1.

Turner, J., 1986: Turbulent entrainment: The development of the entrainment assumption, and its application to geophysical flows. J. Fluid Mech., 173, 431-471, https://doi.org/10.1017/ S0022112086001222.

Warner, J., 1955: The water content of cumuliform cloud. Tellus, $\mathbf{7}$, 449-457, https://doi.org/10.3402/tellusa.v7i4.8917.

Warren, R. A., H. Richter, H. A. Ramsay, S. T. Siems, and M. J. Manton, 2017: Impact of variations in upper-level shear on simulated supercells. Mon. Wea. Rev., 145, 2659-2681, https:// doi.org/10.1175/MWR-D-16-0412.1.

Weisman, M. L., and J. B. Klemp, 1982: The dependence of numerically simulated convective storms on vertical wind shear and buoyancy. Mon. Wea. Rev., 110, 504-520, https://doi.org/ 10.1175/1520-0493(1982)110<0504:TDONSC >2.0.CO;2.

— , and R. Rotunno, 2000: The use of vertical wind shear versus helicity in interpreting supercell dynamics. J. Atmos. Sci., 57, 1452-1472, https://doi.org/10.1175/1520-0469(2000)057<1452: TUOVWS $>2.0 . \mathrm{CO} ; 2$.

Yeo, K., and D. M. Romps, 2013: Measurement of convective entrainment using Lagrangian particles. J. Atmos. Sci., 70, 266277, https://doi.org/10.1175/JAS-D-12-0144.1. 